Session 3230

\title{
Standardizing Outcomes Assessment Allows Faculty to Focus on Student Learning
}

\author{
Gregory G. Kremer \\ Ohio University
}

I. Benefits of standard procedures and templates for assessment and continuous improvement

Outcomes assessment is best viewed as a means to an end, not a goal in itself. It is a tool meant to produce improved student learning (both in terms of what is being learned and how well it is being learned), so we must avoid the trap of spending all our time and energy on assessment and not having any left to make the changes necessary for improved learning. Most faculty members are already overloaded with teaching, research and service responsibilities, so even if they believe assessment is a useful activity they will often resist it as much as possible to avoid the extra workload. The key to overcome this resistance is to 1) make assessment an integral part of the basic course design structure and 2) provide templates and standard procedures for the faculty to follow.

Providing standard assessment procedures does not take away from faculty creativity and involvement in the assessment and continuous improvement process, it just focuses it on the most important items. The key is to communicate clearly the important information that must be collected for program assessment purposes, reducing time wasted by individual faculty thinking about the assessment process and allowing them to focus their time and creative energy on the design of the overall curriculum and the learning activities within the courses that will best help students to achieve the program outcomes. Use of a standardized backward course design process based on program and course outcomes can be very useful here. One example of outcomes-based course planning is given in "Understanding by Design." "Even with a good outcomes-based course design instructors still have to evaluate student performance on the assessment activities for each outcome, but they get to spend most of their time on activities directly related to improving student learning rather than on individually developing procedures and protocols for collecting and evaluating assessment data. When properly implemented, a standardized backward course design process can actually increase creativity by providing a framework within which the faculty can creatively generate learning and assessment activities. This is in agreement with the anonymous quote that states: "standardization is the friend of creativity".

An additional benefit of standardized procedures and templates is that they help organize the overall continuous improvement process. At the beginning of a course, a course design template helps to get all instructors to seriously consider outcomes-based course design rather than "winging it" or just teaching the course the way it has always been done. Standard templates can also give prominence to "closing the loop" activities to make sure that continuous improvement is not ignored, a real possibility in the normal end of the term grading and assessment rush and 
the shift into preparing for the next academic term. Usually the closing the loop actions do not take a significant amount of time, but for maximum effectiveness they must be completed, documented and discussed during and just after the course is finished while the results of what worked and what didn't work are still fresh in the instructor's mind. An instructor reflection template that guides the definition of planned changes for continuous improvement based on active reflection at the end of a course greatly simplifies the preparatory work that needs to be done the next time the course is taught. Procedures and templates for "area of expertise committee" reviews and discussions offer a great opportunity for mentoring, sharing best practices, and encouraging the implementation of applicable pedagogy (for instance to encourage the use of active learning with attention to learning principles) when there are gaps between the actual and desired student performance relative to achievement of a particular outcome. Finally, templates for yearly faculty review reports can ensure that a full-faculty discussion concerning assessment evidence will occur and that it will result in a prioritized list of actions for continuous improvement to be implemented in the next academic year.

\section{Developing standard procedures and templates for your program}

Numerous examples of the procedures and forms used by engineering programs for guiding and documenting the assessment and continuous improvement process are available. A benchmarking study conducted during the summer of 2002 found that programs throughout the country were using standard forms and worksheets for numerous purposes, including guiding the development of assessment methodology for a particular outcome in a particular course, documenting outcomes and assessment methods, guiding and documenting the outcomes-based course design process, and documenting assessment evidence and actions for improvement. For example, Rose-Hulman Institute of Technology uses a "Student learning objective assessment planning matrix" performance criteria that demonstrate achievement of the objectives, the strategy for helping students achieve the performance criteria, and the assessment details. Some engineering programs at North Carolina State University use an "Assessment plan worksheet to determine assessment methodology"3 to guide and document all of the assessment details for each particular outcome in a particular course, while those at the University of Maine use an ABET template for "Course objectives, outcomes and assessment methods" to document course information and assessment information in a compact form. The University of Iowa Mechanical Engineering program uses two templates for outcomes-based course design and continuous improvement, a "Course outcomes worksheet" that deals with the instructional approaches used to achieve the outcomes and a "Course assessment report" that summarizes assessment findings and actions for improvement ${ }^{5}$.

Although learning from these and other examples of what engineering programs have done to organize their assessment process is highly recommended, it is important that your program develops an assessment plan and procedures that are consistent with your resources, mission and objectives. Also, autocratically creating a set of standard procedures and templates (even if they are based on good research) and requiring the faculty to use them will likely result in resentment and resistance rather than compliance. A better way to get faculty buy-in is to involve the faculty in the process of defining the standard procedures that will be used by your department. To get started it is usually best to standardize around existing best practices within the 
department, using best practices identified by benchmarking and other research to fill in any gaps. The "standardized materials" that are most helpful are usually checklists and templates, where the goal is to maximize the useful assessment data generated while minimizing the time and thinking that must be devoted to the actual assessment. Next, run a pilot program with these initial procedures and templates and use faculty feedback from the pilot study to improve them prior to requiring their use in all courses. Additionally, a continuous improvement process should be put in place to make sure that future lessons learned are used to improve the forms and procedures.

Although it is a good start, making standard forms and templates or publishing guidelines is not sufficient in itself. Some type of training or assistance must be provided as faculty members use the forms the first few times. One training strategy that works well is frequent review meetings at the start of the implementation in which faculty members present the forms they have developed for the courses they are teaching that quarter. This provides a forum for discussion, a way to highlight and pass on best practices, a means for developing better understanding of appropriate learning activities and assessment activities, and a better understanding of the entire curriculum for all members of the department.

\section{Examples of standard procedures and templates}

As you develop templates and procedures for your program, you will have to answer questions such as: 1) What should be included in the templates and standard procedures? 2)How much guidance should be given for defining the assessment activities? 3) How much outcomes-based course design information should be required? The following discussion and examples illustrate how these questions were answered in the mechanical engineering program at Ohio University.

We have found it useful to organize the overall ABET 2-loop process with a sequence of linked flowcharts and checklists so that all faculty members can see in a glance both the big picture on the program level and the specific activities required in each course. The highest level flowchart is beyond the scope of this paper but interested readers can find it on our website (http://webme.ent.ohiou.edu/ABET). The one-page flowchart that serves as a reminder to encourage all faculty members to complete their assessment responsibilities (The Outcomes Assessment Plan Faculty Responsibility Flowchart) is included as Table 1 at the end of this paper. This organizing flowchart makes reference to the forms and templates that control the actual assessment activities on the course level (Course design template and assessment form), the area of expertise committee level (Area of Expertise Committee report template), and the program level (High-level outcomes faculty review report template).

The "Course design template and assessment form" (excerpts shown in Table 2) has three sections and a checklist to structure and guide the course design and assessment activities. The course design section defines the program and course outcomes that are assessed in the course and provides structure and guidance for defining the learning activities used to help students achieve the outcomes and the performance criteria to be used as direct assessment evidence to demonstrate that the students achieved the outcomes. The student survey section provides a survey instrument with adequate instructions and focused questions to ensure that student survey data is as useful as possible. The Instructor reflection report focuses the instructor on addressing 
key issues for course improvement, program improvement, and process improvement. The checklist serves as a reminder so that all assessment related activities are done in a timely manner.

The process of actually defining program outcomes and the corresponding specific/measurable outcomes and performance criteria is extremely important but is dealt with in many other sources and is beyond the scope of this paper. The sections on course design, assessment evidence, and surveys will be addressed in some detail since they are very important to the usefulness of the templates.

Prior to assessing student achievement of an outcome, students should have experienced multiple learning activities related to the outcome (in previous courses and/or in multiple points within the course where the outcome is actually assessed). Learning activities are the instructional techniques and activities that are use to help the students master a certain topic or skill. Common learning activities include readings, lectures, discussions, demonstrations, active learning exercises, homework exercises, and even projects for which sufficient formative feedback is given. Pedagogical research has shown that mastery learning techniques that use lots of feedback and recycling (reviewing and redoing work until the required performance level is clearly demonstrated) can be effective in helping students achieve certain outcomes ${ }^{6}$. In order to maintain academic freedom and encourage teaching excellence and creativity, it is best to specify only that outcomes-based learning activities be defined rather than specifying the types of learning activities that the instructors should use.

When it comes to assessing student performance, there is no substitute for evaluation of actual student work on a well-designed assessment activity with a clearly defined set of performance criteria incorporated in an easy to apply assessment rubric. Appropriate assessment activities depend on the type of skill or knowledge being assessed and the performance level desired, but generally they will be focused quiz or exam questions, sections of a project report, a demonstration or presentation, an oral exam, or a reflection paper. One of the important issues (and the reason that a blanket course grade is not sufficient for outcomes assessment) is to make sure the assessment activity is focused on one particular outcome and that it is relatively easy to tell from the student's performance on the activity whether or not they achieved the outcome. Authentic assessment methods, or those in which the student must demonstrate achievement of the outcome in a setting that is most real or authentic (a project or well-conceived exam question) rather than contrived (some ill-conceived and time restricted test questions) are preferred ${ }^{1}$.

One of the problems with many assessment plans is an over-reliance on surveys and other indirect assessments and little or no direct assessment of student work. Surveys and end-ofprogram assessments are necessary parts of an overall assessment plan but they are not sufficient. In fact, since most students are not really qualified to judge whether or not they achieved a certain outcome, student surveys are most useful in providing information for continuous improvement rather than for assessment. For example, students can probably give useful information about the learning activities (all course-related activities designed to help the students achieve the outcomes) and assessment activities (a specific activity like an exam question or a project activity that is designed to assess achievement of a specific outcome), and 
that information can be very important in modifying these activities to better address student needs. However, what you get out of the surveys is largely dependent on the work put in to preparing them and preparing the students to give useful and meaningful feedback. For these surveys to be useful the students must know what the outcomes are from the start of the class, they must know what learning and assessment activities relate to each outcome, and they must be convinced that it is worth their time to provide detailed feedback and that it will be seriously considered for improving the course. This preparatory work should be standardized so that faculty members do not have to create their own surveys and communication methods. One way to do this is with checklist items that remind instructors to communicate the outcomes and share the course design forms with the students (See checklist in Table 2), and standard survey forms and questions with a detailed introduction to remind the students of their important role in the assessment and continuous improvement process (See survey form in Table 2).

The course design and assessment form presented in Table 2 bears a similarity to a course portfolio $^{7}$ in that it requires faculty to look more closely at course outcomes and course design to help students meet those outcomes, and to draw conclusions about the successes and needed improvements in the course. As with course portfolios, a side benefit of these forms is that they are available for other instructors to read, review and think about, and a collection of best practices from the forms can be used as a pedagogical text to teach others. In fact, this review and discussion process can also be formalized as shown by the "Area of Expertise Committee report template" in Table 3 and the "High-level outcomes faculty review report template" in Table 4. The most important features of these forms are to make sure that these reviews and discussions actually happen, to make sure they are focused on continuous improvement, and to make them as efficient as possible by essentially creating the agenda based on the items that need responses in the report template.

In summary, if faculty members are clearly informed of their expectations related to assessment and continuous improvement and are given the resources to meet these expectations, your program will likely have good faculty buy-in and success in implementing your assessment plan. One of the most efficient ways for communicating the expectations and providing the assistance needed for outcomes-based course design and assessment activities is the use of properly developed (and continuously improved) templates and standard procedures. I encourage you to use them in your program and give the faculty the task of developing creative learning activities rather than trying to develop new assessment procedures. 


\section{Table 1: Outcomes Assessment Plan Faculty Responsibility Flowchart}

Each quarter check the action items list in the most recent Faculty Program

Review Report and implement any items pertaining to the courses that you teach

Each time you teach a required undergraduate course, check the most recent list of specific and measurable student outcomes to identify outcomes that must be assessed in the course

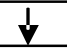

If there are outcomes that must be assessed in your course, follow the procedures for design/planning of tollgate courses in the Course Design and Assessment Form*
If there are no outcomes that must be assessed in your course, fill out part 1 of the Course Design and Assessment Form* to support the continuous improvement effort
Teach course using your individual teaching style, constrained only by the need to conduct the learning activities and assessment activities identified in the outcomes-based course design form you generated for the course, and certify that all students receiving a passing grade have achieved all tollgate outcomes

\section{$\checkmark$}

Assess all of the tollgate outcomes in the course per sections 2 and 3 of the Course Design and Assessment Form, using the Learning Outcomes Assessment $\underline{\text { Checklist during the course to make sure all assessment evidence is collected }}$
Teach course using your individual teaching style to meet your individual course outcomes (that support the program-level outcomes)

At the end of every academic quarter, participate in informal Area of Expertise Committee reviews of relevant assessment data

At the end of every academic year, participate in generating the Area of Expertise Committee

Yearly Report* with recommended action items for continuous improvement

At the end of every academic year, participate in yearly faculty objectives evaluation/high-level outcomes assessment review, which generates a Faculty Program

$\underline{\text { Review Report* }}$ with specific action items for continuous improvement

* The "Course design template and assessment form", the "Area of Expertise Committee report template", and the "High-level outcomes faculty review report template" control the actual assessment activities on the course level, the area of expertise level, and the program level. See the standard forms for additional details and information. 
Table 2: Course design template and assessment form

\begin{tabular}{|l|l|l|}
\hline Course \#: MEXXX & Course Title: Insert Title & Instructor: Insert Name \\
\hline
\end{tabular}

\begin{tabular}{|l|l|l||}
\hline \hline Academic year and quarter: & Prerequisites: & Prerequisite for: \\
\hline Catalog Description: & & \\
\hline Credit hours and Class/Laboratory Schedule: & \\
\hline Textbooks and/or other Required Materials: & \\
\hline \hline
\end{tabular}

\section{Area of Expertise Review Committee: Insert Name}

Section I: Course design (Identify learning activities, assessment evidence, and certification procedures to ensure student achievement of outcomes)

- Address all outcomes individually or address multiple outcomes in combination, whichever is more efficient

- Please identify all items that have been changed for continuous improvement since the last time this course was taught. Use a bold (CI) designation.

PART 1) COMPLETE FOR ALL SPECIFIC PROGRAM OUTCOMES ASSESSED IN THIS COURSE (I.E. ALL TOLLGATE OUTCOMES)

\section{Mastery Level Outcomes}

1-3.1) An ability to perform statistical data analysis of univariate and bivariate data sets

1-3.1) Learning Activities (Instructional methods in this course, plus list of previous courses or activities that directly support this outcome)

1-3.1) Assessment Evidence (Performance Criteria)

1-3.1) Certification Procedure (Procedure to ensure all students who pass this course have met the outcome at the required level)

Part 2) Complete for all other course outcomes, including non-tollgate specific program outcomes and outcomes that support the specific program outcomes. (Note that formal assessment is not required for these outcomes - they are identified for purposes of efficient course design and to support continuous improvement efforts for all program outcomes.)

Other Student Learning Outcomes for this Course

[Identify all additional outcomes here by number and description (required for all courses); include course info related to outcomes as desired]

1-5.5) The ability to use general engineering analytical software (for example MATLAB) as a tool for solution of common engineering problems (using capabilities such as numerical methods, vector analysis, and matrix operations) [example, replace with other outcomes]

\section{Section II: Student survey to evaluate outcomes and processes (required for all tollgate courses)}

Please complete this survey dealing with the program outcomes assessed in this course, in each case selecting the appropriate response. Note the following interpretations of the 4-point rating scale. [SA=Strongly Agree (excellent, no changes required), $\mathrm{A}=$ Agree (Good, some improvement possible), $\mathrm{D}=$ Disagree (Fair, some improvement needed), $\mathrm{SD}=$ Strongly Disagree (Poor, significant improvement required)]. Your input is most valuable if you seriously consider each rating based on your experience this quarter, and especially if you add comments and/or suggestions for improving the course and/or the ME curriculum to help you better achieve each outcome.

Mastery level $=$ Ability plus understanding as gained by reflection and redoing work until it is satisfactory Competence $=$ ability on a problem-solving level Awareness $=$ Familiarity or knowledge 


\begin{tabular}{|c|c|}
\hline $\begin{array}{c}\text { SURVEY QUESTIONS RELATED TO LEARNING OUTCOMES (LO) } \\
\text { ASSESSED IN THIS COURSE }\end{array}$ & $\begin{array}{l}\text { Survey question } \\
\text { responses }\end{array}$ \\
\hline \multicolumn{2}{|l|}{ Mastery Level Outcomes } \\
\hline \multicolumn{2}{|c|}{$\begin{array}{l}\text { 1-3.1) An ability to perform statistical data analysis of univariate and bivariate data sets [example, replace with any } \\
\text { mastery level outcomes] }\end{array}$} \\
\hline $\begin{array}{l}\text { S1) This learning outcome and its required mastery level were clearly communicated } \\
\text { to me early in this course. }\end{array}$ & $\begin{array}{l}\text { SA A } \quad \text { D } \quad \text { SD } \\
\text { Comments/suggestions } \\
\text { for improvement: }\end{array}$ \\
\hline $\begin{array}{l}\text { S2) The learning activities associated with this outcome (as defined in the course } \\
\text { design template) helped me to achieve this outcome at the required mastery level. }\end{array}$ & $\begin{array}{l}\text { SA A D SD } \\
\text { Comments/suggestions } \\
\text { for improving learning } \\
\text { activities: }\end{array}$ \\
\hline $\begin{array}{l}\text { S3) The assessment activities and the mastery learning procedures used for this } \\
\text { outcome (as defined in the course design template) were an appropriate means for } \\
\text { measuring and ensuring my achievement of this outcome at the required mastery level. }\end{array}$ & $\begin{array}{r}\text { SA A } \quad \text { D } \text { SD } \\
\text { Comments/suggestions } \\
\text { for improving } \\
\text { assessment activities: }\end{array}$ \\
\hline S4) I believe that I achieved this learning outcome at the required mastery level. & $\begin{array}{l}\text { SA A D SD } \\
\text { Comments/suggestions } \\
\text { for improvement: }\end{array}$ \\
\hline
\end{tabular}

[Note: It is highly recommended that you implement this survey in an online format (i.e. using Blackboard) to simplify compilation of results and comments]

\section{Section III: Instructor Reflection Report (required for all tollgate courses)}

Please complete the form below for all outcomes, in each case selecting the rating (Inadequate: unacceptable, improvements are required; Adequate: acceptable, but improvements are desirable; Exceptional: no improvement needed) that corresponds to your opinion of the learning activities or the assessment evidence used this quarter. Additionally, based on your experience this quarter and your review of the student survey results justify your evaluation and identify your ideas/plans for changing the course and/or the ME curriculum in an attempt at improving student achievement of each outcome. Note that all plans for continuous improvement (CI) should be discussed in the quarterly "Area of Expertise" review meetings, and all plans that are accepted for implementation must be reflected in the course design template the next time the course is taught.

\begin{tabular}{||l|l|l||}
\hline \multicolumn{1}{|c|}{$\begin{array}{c}\text { Learning Outcomes (LO) } \\
\text { Assessed in This Course }\end{array}$} & $\begin{array}{c}\text { Evaluate assessment evidence and } \\
\text { mastery learning procedures and } \\
\text { identify plans for CI }\end{array}$ & $\begin{array}{c}\text { Evaluate learning activities and } \\
\text { identify plans for CI }\end{array}$ \\
\hline \hline Mastery Level Outcomes & \multicolumn{2}{|c||}{} \\
\hline $\begin{array}{l}\text { 1-3.1) An ability to perform } \\
\text { statistical data analysis of univariate } \\
\text { and bivariate data sets [example, } \\
\text { replace with any mastery level } \\
\text { outcomes] }\end{array}$ & $\begin{array}{l}\text { Inadequate Adequate Exceptional } \\
\text { Justification and plans for CI: }\end{array}$ & $\begin{array}{l}\text { Inadequate Adequate Exceptional } \\
\text { Justification and plans for CI: }\end{array}$ \\
\hline \hline
\end{tabular}

Are any changes required to the learning outcomes required for this course (wording of outcomes

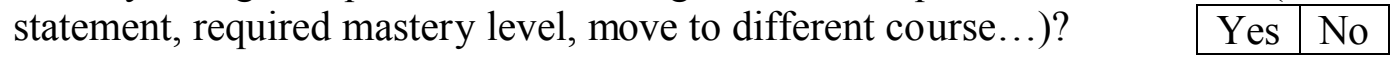

If yes, list the recommend changes.

Summarize the action items resulting from this assessment (for discussion at the Area of Expertise Committee review): 
Learning Outcomes Assessment Checklist (required for all tollgate courses)

\begin{tabular}{|c|c|c|}
\hline Course \#: & Course Title: & Instructor: \\
\hline Completed & $\begin{array}{c}\text { Checklist of items that must be completed and documented for each } \\
\text { outcome each time the course is taught }\end{array}$ & Page \# \\
\hline Date & $\begin{array}{l}\text { Review the assessment evidence (including the student surveys and the } \\
\text { instructor reflection report) from the last time this course was taught, } \\
\text { review all action items for continuous improvement in the most recent } \\
\text { yearly faculty program review report, and implement all action items } \\
\text { related to this course. Based on these reviews and on recommended } \\
\text { pedagogical practice, complete Section I of the course design template } \\
\text { and assessment form and prepare the student survey instrument as } \\
\text { described in Section II (prior to the first class meeting). }\end{array}$ & $\#$ \\
\hline Date & $\begin{array}{l}\text { Clearly communicate to the students the intended learning outcome(s) for } \\
\text { this course, the course design to achieve the outcomes (including the } \\
\text { mastery learning* procedures that will be used to ensure that all students } \\
\text { who pass the course have met the tollgate outcomes at the required level), } \\
\text { and their important role in the outcomes evaluation process. Provide the } \\
\text { students with copies of sections I and II of the course design template } \\
\text { and assessment form (in the first week of the quarter). }\end{array}$ & \# \\
\hline Date & $\begin{array}{l}\text { For all tollgate outcomes, clearly communicate to the students in written } \\
\text { form the basis for the grading of the assessment activities and how the } \\
\text { grades reflect achievement of the learning outcome. Save copies of the } \\
\text { documents (for example the grading rubrics) that clearly indicate how the } \\
\text { grading information was communicated to the students and how the grading } \\
\text { procedure was implemented. }\end{array}$ & \# \\
\hline Date & $\begin{array}{l}\text { For all tollgate outcomes, save representative examples of the assessment } \\
\text { evidence (i.e. the student work on the assessment activities) in an attempt to } \\
\text { demonstrate what you consider acceptable evidence of student achievement } \\
\text { of the outcome at the required level and to demonstrate the application of } \\
\text { the grading policy and the mastery learning procedure. }\end{array}$ & \# \\
\hline Date & $\begin{array}{l}\text { Conduct the student survey to evaluate outcomes and processes (using } \\
\text { the standard survey form) and save copies of the results. }\end{array}$ & \# \\
\hline Date & $\begin{array}{l}\text { Complete an instructor reflection report (using the standard template) } \\
\text { with a focus on closing the loop for continuous improvement of the } \\
\text { program and the process, and save a copy of the completed form. }\end{array}$ & $\#$ \\
\hline
\end{tabular}

* The methods used to provide formative feedback and to require recycling (reviewing and redoing work until the required performance level is clearly demonstrated) 


\section{Table 3: Area of Expertise Committee Report Template}

\begin{tabular}{|l|l|}
\hline Academic year of committee review & $2002-2003$ \\
\hline
\end{tabular}

Based on the Committee's review of the assessment evidence for all detailed outcomes in our Area of Expertise, including but not limited to the relevant course design and assessment forms for the courses in this area, we provide the following responses representing our level of agreement with two main issues relative to the outcomes: 1) The assessment evidence used for each specific outcome appears to be a valid and reliable indicator of whether or not the students achieved the outcome at the required level, and 2) The assessment evidence presented for each specific outcome shows that all students who passed the course during this academic year actually did achieve the outcome at the required mastery level.

Circle the response representing the committee's level of agreement with each statement ( $\mathrm{SA}=$ Strongly Agree, $\mathrm{A}=$ Agree, $\mathrm{D}=$ Disagree, $\mathrm{SD}=$ Strongly Disagree).

\begin{tabular}{||l|l|l||}
\hline \multicolumn{1}{|l||}{ Detailed Learning Outcomes in this area of expertise } & $\begin{array}{c}\text { Assessment } \\
\text { evidence is } \\
\text { valid and } \\
\text { reliable }\end{array}$ & $\begin{array}{c}\text { Evidence } \\
\text { shows all } \\
\text { students } \\
\text { achieved } \\
\text { outcome }\end{array}$ \\
\hline \hline Mastery Level Outcomes & SA A D SD & SA A D SD \\
\hline $\begin{array}{l}\text { 1-3.1) An ability to perform statistical data analysis of univariate and } \\
\text { bivariate data sets }\end{array}$ & \\
\hline \hline Competence Level Outcomes & SA A D SD & SA A D SD \\
\hline Add a line for every competence level outcome & \\
\hline \hline Awareness Level Outcomes & SA A D SD & SA A D SD \\
\hline Add a line for every awareness level outcome &
\end{tabular}

Justification for the responses:

Provide some discussion or justification for all responses. Additionally, any responses of D or SD for any outcomes must be accompanied with a detailed discussion of the reason for the low rating and a plan of action for rectifying the problem.

Recommended Action Items for Continuous Improvement:

Based on the committee's review of the current program outcomes statements, the curriculum and learning activities currently used to help students achieve the outcomes, and the assessment evidence used to assess achievement of the outcomes, we make the following recommendations for continuous improvements of the program (to improve student performance) and/or the assessment process (to better assess student performance).

\begin{tabular}{||l|c||}
\hline \multicolumn{1}{|c||}{ Item } & $\begin{array}{c}\text { RECOMMENDED ACTIONS FOR CONTINUOUS } \\
\text { IMPROVEMENT }\end{array}$ \\
\hline Program outcomes statements & \\
\hline Curriculum and learning activities & \\
\hline Evidence used for assessment & \\
\hline Other & \\
\hline \hline
\end{tabular}

Signature of committee chairman

Date

Proceedings of the 2003 American Society for Engineering Education Annual Conference \& Exposition Copyright $($ C 2003, American Society for Engineering Education 
Table 4: High-Level Outcomes Faculty Review Report Template

\begin{tabular}{|l|l|}
\hline Academic year: & \\
\hline Date of review meeting & \\
\hline
\end{tabular}

High-level outcomes assessment

Based on the ME faculty review of the assessment evidence, including the Area of Expertise Committee reports on assessment of all of the detailed outcomes, we provide the following responses representing our level of agreement with the program outcome statements.

Circle the appropriate response ( $\mathrm{SA}=$ Strongly Agree, $\mathrm{A}=$ Agree, $\mathrm{D}=$ Disagree, $\mathrm{SD}=$ Strongly Disagree).

\begin{tabular}{|c|c|c|}
\hline 1-1. (ABET-c) & $\begin{array}{l}\text { OU ME graduates will demonstrate an ability to design a system, component, } \\
\text { or process to meet desired needs }\end{array}$ & SA A D SD \\
\hline 1-2. (ABET-e) & $\begin{array}{l}\text { OU ME graduates will demonstrate an ability to identify, formulate, and solve } \\
\text { engineering problems }\end{array}$ & SA A D SD \\
\hline 1-3. (ABET-b) & $\begin{array}{l}\text { OU ME graduates will demonstrate an ability to design and conduct } \\
\text { experiments, as well as to analyze and interpret data. }\end{array}$ & SA A D SD \\
\hline 1-4. (ABET-d) & $\begin{array}{l}\text { OU ME graduates will demonstrate an ability to function on multi- } \\
\text { disciplinary teams }\end{array}$ & SA A \\
\hline 1-5. (ABET-k) & $\begin{array}{l}\text { OU ME graduates will demonstrate an ability to use the techniques, skills, } \\
\text { and modern engineering tools necessary for engineering practice }\end{array}$ & SA A D SD \\
\hline $\begin{array}{l}2-1 .(\text { ABET-a, } \\
\text { ASME-1,2,\&3) }\end{array}$ & $\begin{array}{l}\text { OU ME graduates will demonstrate a familiarity with statistics and linear } \\
\text { algebra, a knowledge of chemistry and calculus-based physics (with depth in } \\
\text { physics), and an ability to apply their knowledge of advanced math (through } \\
\text { multivariate calculus and differential equations), science, and engineering. }\end{array}$ & SA A D SD \\
\hline 2-2. (ABET-i) & $\begin{array}{l}\text { OU ME graduates will demonstrate a recognition of the need for, and an } \\
\text { ability to engage in life-long learning }\end{array}$ & SA A D SD \\
\hline 3-1. (ABET-g) & OU ME graduates will demonstrate an ability to communicate effectively & SA A D SD \\
\hline 4-1. (ABET-f) & $\begin{array}{l}\text { OU ME graduates will demonstrate an understanding of professional and } \\
\text { ethical responsibility }\end{array}$ & SA A D SD \\
\hline 4-2. (ABET-h) & $\begin{array}{l}\text { OU ME graduates will have the broad education necessary to understand the } \\
\text { impact of engineering solutions in a global and societal context. }\end{array}$ & SA A D SD \\
\hline 4-3. (ABET-j) & OU ME graduates will demonstrate a knowledge of contemporary issues. & SA A D SD \\
\hline
\end{tabular}

Justification for the responses:

Provide some discussion or justification for all responses, including identification of all evidence reviewed (transcripts, co-curricular resumes, summary reports, advisory board reports, ...). Additionally, any responses of $D$ or SD for any outcomes must be accompanied with a detailed discussion of the reason for the low rating and a plan of action for rectifying the problem.

Evaluation of Objectives

Based on the ME faculty review of the evidence for evaluating the program's achievement of its objectives, we provide the following responses representing our level of agreement with the program objective statements.

Circle the appropriate response ( $\mathrm{SA}=$ Strongly Agree, $\mathrm{A}=$ Agree, $\mathrm{D}=$ Disagree, $\mathrm{SD}=$ Strongly Disagree).

\begin{tabular}{|l|l|l|}
\hline 1 & $\begin{array}{l}\text { OU ME graduates are prepared to practice as entry-level mechanical engineers (Engineers in } \\
\text { Training) in a range of specialty areas, including design of thermal/fluid systems, design of } \\
\text { mechanical systems, manufacturing, materials, or other related areas; or (for those graduates } \\
\text { with the ability and the desire) to gain entry to and successfully complete an advanced } \\
\text { degree program in engineering, business, medicine, or any other related field }\end{array}$ & D SD \\
\hline 2 & $\begin{array}{l}\text { OU ME graduates have a strong fundamental scientific and technical knowledge base and a } \\
\text { proficiency in learning, using, and understanding technology to serve as a foundation for } \\
\text { engineering practice and life-long learning. }\end{array}$ & SA A D SD \\
\hline 3 & OU ME graduates are proficient technical communicators, able to completely and clearly & SA A D SD \\
\hline
\end{tabular}

Proceedings of the 2003 American Society for Engineering Education Annual Conference \& Exposition Copyright $(\mathrm{C}$ 2003, American Society for Engineering Education 


\begin{tabular}{|c|c|c|}
\hline & $\begin{array}{l}\text { document analytical and experimental work, provide a clear and concise representation of } \\
\text { results and conclusions, and prepare and deliver effective technical reports and } \\
\text { presentations. }\end{array}$ & \\
\hline 4 & $\begin{array}{l}\text { OU ME graduates are prepared to be informed, responsible citizens and productive, ethical } \\
\text { professionals in the global economy. }\end{array}$ & SA A D SD \\
\hline
\end{tabular}

Justification for the responses:

Provide some discussion or justification for all responses, including identification of all evidence reviewed (alumni surveys, advisory board reports, ...). Additionally, any responses of D or SD for any objectives must be accompanied with a detailed discussion of the reason for the low rating and a plan of action for rectifying the problem.

Action Items for Continuous Improvement:

All action items from the committee reports for the assessment of the detailed outcomes and the advisory board program review and the alumni survey summary should be reviewed and those that are endorsed by the overall faculty should be presented here.

Bibliography

1. Wiggins, G. \& McTighe, J., "Understanding by Design”. Association for Supervision and Curriculum Development, 1998.

2. http://www.rose-hulman.edu/irpa/old/Gloria/Matrix_legal.PDF

3. http://www.engr.ncsu.edu/abet/criterion-3/assessment\%20plan\%20format\%20-\%20example.htm

4. http://www.umeme.maine.edu/

5. http://css.engineering.uiowa.edu/ mech_eng/abet/abetprogramsandcourseassessment3.htm

6. Wankat, P. \& Oreovicz, F., "Mastery Learning", ASEE Prism, November 2001, p. 38.

7. "Course Portfolios: To Preserve and Refine Good Teaching Ideas", The Teaching Professor, August/September 2001

\section{GREGORY G. KREMER}

Dr. Kremer is an Assistant Professor and leader of Assessment and CI in the Mechanical Engineering Department at Ohio University. His area of expertise is Mechanical Systems Design, and he has extensive industrial experience in this area. Dr. Kremer received his B.S. degree in Mechanical Engineering from Rose-Hulman Institute of Technology in 1989 and his Ph.D. degree in Mechanical Engineering from the University of Cincinnati in 1998. 